quoted as suggesting that the Upper Cave people may represent the ancestors of the Amerindian population in process of migration to the crossing from Asia to America. Among the numerous artefacts which have been found in association with the remains - stone and bone implements, perforated teeth, shells, and stones used for ornament--several can be traced to an origin varying from 100 to 200 miles 8way. This lends support to the view that these were a far-travelled people in a stage of further migration. Injuries shown by the skulls indicate that all the members of the group met with a violent end.

\section{British Optical Instrument Display at World's Fair}

THE British optical instrument industry, through the Scientific Instrument Manufacturers' Association, is exhibiting a cross-section of the products of the industry at the World's Fair, New York. Eighteen firms are participating, and the exhibit is arranged in four showcases each $8 \mathrm{ft}$. by $3 \mathrm{ft}$. 6 in. by $3 \mathrm{ft}$., also a series of showcases mounted in two panels $24 \mathrm{ft}$. by $3 \mathrm{ft}$. stretching from a centre piece formed of a large mass of optical glass, and two photo murals $16 \mathrm{ft}$. by $12 \mathrm{ft}$. with showcards let in. The exhibitor firms have regarded the exhibit from a 'prestige' aspect, and by mutual arrangement each firm has endeavoured to send a limited exhibit of its specialities selected so that there may be no overlapping. In other words, makers of theodolites, levels and microscopes are showing a complete range of products, but built up of several makes rather than various models by each maker for the same purpose. The display is very comprehensive. Both in appearance, finish and presentation it should at least equal anything that has hitherto been devised. It is impossible to refer in the course of a brief note to all the different exhibits. These comprise among the more standard types a course-setting bomb sight, aeroplane sextant, echo depth-sounder, Robbin Hill camera, survey lens for aerial camera, spectrograph, spectrometers, apparatus for measuring pressure in mines and dust counters, measuring microscopes, microtomes, prism binoculars, telescopes, photographie lenses and cameras.

\section{Soil Erosion in Jamaica}

Sorl erosion in Jamaica forms the subject of a bulletin (No. 17) issued by its Department of Science and Agriculture. The greater part of the cultivated land is situated on steep hillsides, gradients of one in one being frequent, so that sheet erosion is the major problem. These slopes were originally covered by dense forest and undergrowth, the clearing of which has resulted in rapid loss of surface soil. The rate of loss depends largely on the crop grown. Bananas and coffee, for example, are comparatively widely spaced and are maintained under clean cultivation so that soil exposure is very serious, though the necessity for drains in the case of bananas somewhat alleviates the situation. Sugar-cane, on the other hand, is an excellent soil conserver as it has an elaborate root system and the trash deposited after reaping forms a protective cover. Of the less im- portant crops the cultivation of yams, sweet potatoes, corn or ginger encourages erosion, but citrus causes little loss as the trees are usually left in the grass cover. Erosion is also promoted by the otherwise valuable system of forking the soil at the end of the dry season to facilitate the penetration of the first rains, and by the improper placing of drains. Other factors which contribute to the problem are the practice of short-period tenancy, which gives the proprietor little interest in conserving the fertility of his land, and the system of renting land for the production of one type of crop only. Some fundamental changes in the current agricultural practices will be needed if further loss of valuable soil is to be prevented.

Earthquakes Recorded in India, January-March, 1938

SEISMOLOGICAL information obtained in India is henceforth to be published quarterly as a separate bulletin. The first of these bulletins (Seis. Bull., Jan.-March 1938, Government of India Meteorological Department, Delhi) has been received. It consists of reports from seven instrumental stations, and non-instrumental reports received at Poona. First is given a list of stations with their latitude and longitude to the nearest minute of are together with other necessary information, and also a list of the instruments and their constants with which each is equipped. For the quarter, Agra records 56 shocks, Bombay 77, Calcutta 89, Colombo 47, Dehra Dun 13, Hyderabad, 41, and Kodaikanal 61. The small number recorded at Dehra Dun may be due to poor instrumental equipment. Records for the observatories are separate, giving in each case date, component, phase, time received, period, amplitude, epicentral distance if determined, and remarks concerning the shock or the reception. The macroseismic evidence collected at Poona is valuable, personal observations numbering 62, 12 being from Drosh. The shock with most macroseismic effect was on March 14. It cracked property at East Khandesh, damaged property at Maheswar (Indore) and damaged property, injuring two children, at East Khandesh. Seismologists will be grateful to those concerned with the report for putting the data obtained in a manner convenient for reference, and for taking the important step of having it published at more frequent intervals.

\section{An Electron Diffraction Camera}

Messrs. W. EDWARds AND Co., Allendale Works, Vaughan Road, London, S.E.5, have recently published details of their Finch electron diffraction camera intended for industrial research. This camera is of the type developed by Prof. G. Ingle Finch, who has done so much to improve the technique of electron diffraction. The camera uses a cold cathode discharge tube as a source of electrons. The fine beam, which is necessary for a sharp diffraction pattern, is obtained by using a series of diaphragms and by focusing the beam upon the screen with a magnetic coil. A useful feature is that both the diaphragm and specimen holders are standardized so that they will fit any of the six ports in the instru- 